\title{
Clinical Practice Guideline for the Management of Neuromuscular Blockade: What Are the Recommendations in the USA and Other Countries?
}

\author{
Réka Nemes ${ }^{1}$ • J. Ross Renew ${ }^{2}$ \\ Published online: 11 April 2020 \\ (C) The Author(s) 2020
}

\begin{abstract}
Purpose of Review This review addresses various societal guidelines, standards, and consensus statements regarding optimal neuromuscular blockade management. We discuss the historical evolution of neuromuscular management as a means of identifying possible future trends.

Recent Findings While a recent international panel of experts has called for abandoning clinical assessment and subjective evaluation using a peripheral nerve stimulator in favor of adopting quantitative monitoring, few anesthesia societies mandate similar practices at the moment.

Summary The current status of neuromuscular monitoring in the world is still variable and unsatisfactory. Nevertheless, a positive trend can be observed in the anesthesia community to adopt and learn this neglected technique. The development of user-friendly monitoring devices should also help this process, but anesthesia national societies still need to do a lot to replace outdated and substandard practices.
\end{abstract}

Keywords Residual neuromuscular blockade $\cdot$ Neuromuscular monitoring $\cdot$ Patient safety $\cdot$ Guidelines $\cdot$ Consensus statement

\section{Introduction}

Seventy years after the introduction of neuromuscular blocking agents (NMBA) into anesthesia practice, anesthesiologists still face challenges with correct management of neuromuscular blockade (NMB). Recovery from NMB, whether spontaneous or pharmacologic, occurs with significant interindividual variability, and can lead to incomplete recovery in many patients [1-3]. In 1979, Viby-Mogensen reported the incidence of postoperative residual neuromuscular blockade

This article is part of the Topical Collection on Neuromuscular Blockade

Réka Nemes

reka.nemes.11@gmail.com

J. Ross Renew

renew.johnathan@mayo.edu

1 Department of Anesthesiology and Intensive Care, University of Debrecen, 98 Nagyerdei krt., Debrecen 4032, Hungary

2 Anesthesiology and Perioperative Medicine, Mayo Clinic Florida, 4500 San Pablo Road, Jacksonville, FL 32224, USA
(RNMB) to be $42 \%$ [4]. Forty years later, the incidence persists between 40 and $60 \%[5-7,8 \cdot 0]$ as an unacceptably high number of patients leave the operating theater with residual paralysis and carry the potential risk for associated postoperative pulmonary and other complications. Neuromuscular blockade could and should be tailored to each patient and surgical scenario. However, anesthesiologists must be willing to master fundamentals of NMB and utilize best practices to avoid the iatrogenic complications associated with RNMB.

Curare was introduced into anesthesia practice in the 1942 by Griffith and Johnson [9] in Canada. Subsequently, Gray and the Liverpool anesthetic technique had a major contribution to its general adoption [10-12]. These pioneers began the process of gathering experience and data with neuromuscular blocking agents, as much remained undiscovered about the neuromuscular junction and relevant pharmacology. It comes as no surprise that Beecher and Todd reported a six-fold increase in the mortality of those patients who received curare in these early days of NMB [13].

The next few decades brought significant discoveries and developments in the field of NMB, their reversal agents, and monitoring techniques. However, there were several detours and even dead ends on the journey to safe management of 
neuromuscular blockade. Numerous pharmacological and monitoring practices emerged that were ultimately found to be inadequate, yet such practices had already become entrenched into routine clinical practice and remain in use today.

\section{Advances in Neuromuscular Blockade Pharmacology}

Until the beginning of the 2000s, the administration of cholinesterase inhibitors, especially neostigmine, was the only way to enhance recovery from neuromuscular blockade. However, the indirect antagonism of non-depolarizing NMBAs has always been unpredictable [3]. Fearing the muscarinic side effects, anesthesiologists were likely to administer lower doses than necessary, or forego its use altogether. If administered too early (train-of-four count $<4$ ), the ceiling effect of these drugs presented an obstacle to hastening recovery [14]. Conversely, there was also a fear that if administered too late, neostigmine itself might cause muscle weakness $[15,16]$. Even if administered in appropriate doses at appropriate levels of NMB, an average of $15 \mathrm{~min}$ is required to achieve adequate recovery defined as a train-of-four ratio $>0.9$ [3]. Due to these difficulties, it is no surprise that neostigmine reversal in the absence of objective monitoring has been shown to not significantly affect the incidence of RNMB [6, 17, 18].

The introduction of sugammadex into clinical practice represented a significant breakthrough in not only the arena of NMB but also anesthesia in general. This drug has a well-defined dosing scale that provides a fast and reliable reversal for aminosteroidal NMBAs from any depth of blockade [19]. To define the optimal dose, anesthesiologists should determine the level of the neuromuscular blockade at the time of sugammadex administration. After the introduction of sugammadex into clinical practice, there was a period in which anesthesiologists hoped that sugammadex reversal would eliminate the need for rigorous monitoring. However, several investigations have demonstrated that sugammadex is not foolproof, and empiric administration that is not based of the degree of block does not eradicate residual neuromuscular block. Kotake et al. reported an incidence of RNMB of $4.3 \%$ in patients receiving sugammadex without monitoring [20]. Additionally, several other cases have been documented in which sugammadex proved ineffective [21], had a prolonged onset of action [22-24], or resulted in recurrence of NMB when sugammadex was used without objective monitoring $[25,26]$.

\section{Peripheral Nerve Stimulators-a Step in the Right Direction}

The first peripheral nerve stimulator (PNS) was developed in 1958 by Christie and Churchill-Davidson [27]. However, in the beginning, only a handful of people had the access to this new technology. Most anesthesiologists had to rely on clinical tests, such as the 5-s head lift, leg and arm lift tests, and the tongue protrusion test to exclude RNMB. Additionally, measuring the tidal volume and relying upon the expected pharmacokinetics (duration of action, reversal time) of NMBAs were also common practices. These early, unreliable practices were the result of both unfamiliarity with the novel PNS technology and the limited availability. However, this time period also spawned important work in the field as anesthesiologists started to compare patients' ability to perform clinical tests to objective electrophysiological measurements of NMB. It became evident that patients could "pass" clinical tests even in the presence of significant RNMB. Most patients are able to maintain a 5 -s head lift test at a train-of-four ratio $<0.5[4,28]$. No single clinical test or a combination of tests has a useful sensitivity $(0.18-0.35)$ or positive predictive value $(0.47-$ 0.52) [29].

With these emerging data, the anesthesia community started to endorse the use of peripheral nerve stimulators. Indeed, these simple hand-held devices were cost-effective, were very easy to use, and gained wide popularity over the years. In two clinical investigations from the 1990s, the clinical use of PNSs decreased the occurrence of RNMB compared with the use of simple clinical examination [30, 31]. However, PNSs possess the inherent limitation, in that the clinician has to rely on subjective (visual or tactile) means to determine the level of NMB. This shortcoming was confirmed since the 1980s, as several investigations demonstrated that human observers are not able to reliably identify the degree of fade (train-of-four ratio > 0.4-0.6), regardless of the pattern of neurostimulation [30, 32-34]. As a consequence of this subjectivity, PNSs proved inferior to objective monitoring devices in preventing RNMB and associated airway complications in two clinical outcome studies [35, 36]. The RECITE and RECITE-US multicenter studies also proved that the common practice of subjective monitoring-guided neostigmine reversal leads to RNMB rates higher than $60 \%$ [6, 8••]. To guarantee adequate recovery, measurement of fade (objective monitoring) is an absolute requirement [37••].

\section{The Introduction of Objective Monitoring}

Objective neuromuscular monitoring (NMM) became widely available after the development of acceleromyography (AMG) in the 1980s $[38,39]$. Compared with the predecessors, the bulky and sophisticated mechanomyography- and electromyography-based devices, the AMG-based monitors proved portable and relatively easy to use. However, clinical tests and peripheral nerve stimulators had already gained wide acceptance, as the older objective monitoring techniques were only available in dedicated centers. In addition, 
anesthesiologists would have to take several additional steps to obtain reliable measurements when using AMG [19]. Without immobilization of the arm and fingers, the use of preload to the thumb, and calibration of the device, AMG measurements can be highly variable [40], which deprives the technique of its credibility in the eyes of clinicians. In a recent Danish survey, $75 \%$ of respondents reported regularly having difficulties with objective monitoring devices (mostly referring to acceleromyography-based devices). The most frequent problems were the fluctuating and unreliable train-offour values as well as error messages from the monitor [41]. Nevertheless, objective NMM has been shown to decrease the incidence of RNMB and postoperative respiratory complications $[35,36]$. In addition, it has been reported that an institutional leader who is dedicated to a comprehensive education and implementation plan of objective monitoring can dramatically decrease the number of RNMB and critical respiratory events [42-46].

For two decades, experts' editorials have advocated the application of objective NMM and universal reversal techniques whenever NMBAs are administered [47-49]. In 2003, Eriksson sent a short and clear message to anesthesiologists calling for objective monitoring whenever NMBA is administered [49]. In 2009, El-Orbany also opined that objective NMM should become standard of care [50]. Unfortunately, the anesthesia community has still not heeded this experts' advice. National surveys from around the world showed that anesthesiologists still rely on the imprecise and antiquated practices of clinical evaluation and subjective assessment [51-54]. In 2010, Naguib et al. conducted a large international survey to measure the knowledge of European and American anesthesiologists in NMB management and survey their clinical practice [55]. The survey clearly showed that inappropriate NMB management still dominates clinical practice worldwide, as $9.4 \%$ of American and $19.3 \%$ of European anesthesiologists claimed never to use NMMs. Europeans were more likely to use objective monitors, while twice as many Americans routinely administered reversal agents at the end of the case (18 vs. 34.2\%) [55]. This survey also revealed that $64.1 \%$ of American and $52.2 \%$ European anesthesiologists believed the incidence of RNMB is $<1 \%$ yet multiple large-scale, contemporary studies have demonstrated the incidence to be between 40 and $60 \%[5-7,8 \cdot \bullet])$. Perhaps as a result of extensive educational efforts [19, 56-58], more recent surveys $[41,59]$ have shown an improvement in general knowledge about neuromuscular blockade management and larger willingness to monitor and administer reversal agents properly. However, such important practice updates have been gradual and slow.

Experts presume several factors have served as obstacles and slowed the progression to widespread utilization of evidence-based NMB management. There has been a paucity of reliable, user-friendly objective neuromuscular monitors
[37••]. In the last several years, various medical device manufacturers have developed their own modular or stand-alone objective monitors, suggesting this issue eventually may be addressed. Fortunately, many of these emerging technologies have emphasized the ease of use to increase the acceptance and popularity of the devices. While validation studies are still in progress, early reports investigating new monitors have been very promising [60-67]. It appears that the anesthesia community will have multiple options to select from when adopting quantitative monitoring. Nevertheless, anesthesiologists will need to be aware of the strength and limitations of the monitoring modalities to select the one that is best tailored to their needs.

Clinicians' (over) confidence in their current clinical practice might be another large obstacle to change [68]. Therefore, experts are encouraging national societies to mandate the use of monitoring devices as a first step [37••]. In 2010, Kopman wrote that "It is time for anesthesia's professional organizations to finally draft evidence-based guidelines detailing how best to monitor and manage the perioperative administration of neuromuscular blocking drugs" [48].

\section{Specialty Society Guidelines and International Panels}

To help and guide national specialty societies and provide clarity in terms and definitions of NMB management, a consensus statement authored by an international panel of experts was published in 2017 [37••]. This statement provided definitions of NMM modalities and standardized descriptor for levels of NMB. The statement proposes that quantitative (objective) NMB monitoring should be used whenever non-depolarizing NMBAs are administered. It also recommended that subjective monitoring and clinical evaluation of muscle strength be abandoned in favor of objective monitoring. However, the panel recognized that replacing conventional PNS devices with quantitative monitoring equipment would take time and education. During this interim period, the use of a PNS in any patient receiving a NMBA should be mandatory $[37 \bullet \bullet]$.

In spite of such efforts, anesthesia leadership has been slow to develop guidelines outlining optimal NMB management. Large anesthesia societies like the European Society of Anaesthesiology (ESA) and the American Society of Anesthesiology (ASA) have abstained from making statements on the subject so far. Interestingly, ESA has recently organized a task force on publishing their first NMB management guideline (personal communication). The 2015 American Standards for Basic Anesthesia Monitoring document authored by the ASA does not mention neuromuscular monitoring as part of the minimum monitoring standards [69]. The ASA Practice Guideline for Postanesthetic Care from 
2013 is also insufficient in addressing optimal NMB care as it states that "assessment of neuromuscular function primarily includes physical examination and, on occasion, may include neuromuscular blockade monitoring." [70]. It is hoped that the alarming numbers of patients with significant RNMB in the recently published RECITE-US study [8・•] will underscore the existing problem and provide the impetus for the American Society of Anesthesiologists to recommend positive changes in the near future. Other large societies also fail to call for quantitative monitoring. Constrained by the resource limitations of low- and middle-income countries, the 2010 World Federation of Societies of Anaesthesiologists (WFSA) International Standards for Safe Practice of Anesthesia recommend the use of PNSs when neuromuscular blocking agents are administered [71].

Nevertheless, smaller national societies have slowly started to take steps forward and include neuromuscular blockade management in their basic anesthesia standards or even develop national guidelines. The specifics of these standards and guidelines are highly variable. This review is not intended to present all available worldwide documents, guidelines, statements, or recommendations, and does not include countries where recommendations are missing. Rather, this review was intended to illustrate the wide spectrum of solutions in the way that various national anesthesia societies handle this important patient safety problem.

\section{National Practice Parameters}

The 2016 Norwegian and 2018 Japanese standards simply advocate the monitoring of neuromuscular function when NMBAs and reversal agents are used [72, 73]. The 2014 Swiss anesthesia standards mandate neuromuscular monitoring when NMBAs are administered without specifying the type of the monitor [74]. The 2019 Dutch anesthesia practice parameters list PNSs as part of minimal monitoring standards and mandate PNS use "for controlling neuromuscular function" whenever NMBAs are administered [75].

The Danish general anesthesia guideline from 2017 states that a nerve stimulator should be used whenever a nondepolarizing muscle relaxant is administered [76]. Despite not calling for quantitative monitoring, Denmark has an advanced monitoring practice that involves quantitative monitoring [41, 51, 77]. A survey in 2017 showed that $58 \%$ of the 653 responding anesthesiologists always use objective monitoring and $86 \%$ in at least three quarter of their patients. Nearly all $(97 \%)$ of the respondents reported having access to objective monitors [41].

The 2017 Australian and New Zealand College of Anaesthetists (ANZCA) Guidelines on Monitoring During Anaesthesia supports objective monitoring by stating that "Neuromuscular function monitoring, preferably quantitative, must be available for every patient in whom neuromuscular blockade has been induced and should be used whenever the anaesthetist is considering extubation following the use of non-depolarising neuromuscular blockade" [78]. The background paper for this guideline also describes the debate on whether to mandate the use of quantitative monitors. Consideration of current cost implications vs. patient benefit has kept ANZCA from taking this step [79]. Nevertheless, it would be interesting to see the impact of this guideline on Australian clinical practice. A survey conducted in 2013 among the anesthesiologists of Australia and New Zealand revealed similar gaps in knowledge and underutilization of objective monitors as in other parts of the world [53]. Over $35 \%$ of respondents never or almost never monitored NM function at that time, and $40 \%$ had no access to quantitative devices [53].

The Association of Anaesthetists of Great Britain and Ireland also used a strict tone in their Recommendations for Standards of Monitoring during Anaesthesia and Recovery in 2015 [80]. The document states that "a peripheral nerve stimulator is mandatory for all patients receiving neuromuscular blockade drugs. Peripheral nerve stimulator monitors should be applied and used from induction (to confirm adequate muscle relaxation before endotracheal intubation) until recovery from blockade and return of consciousness ... A quantitative peripheral nerve stimulator is required to accurately assess the train of four ratio, but other stimulation modalities (e.g. double burst or post tetanic count) can also be used for assessment. Anaesthetic departments are encouraged to replace existing qualitative nerve stimulators with quantitative devices" [80].

It would be reasonable to suppose that these guidelines contributed to the change in monitoring practices in Great Britain. In 2007, a survey by Grayling showed that $62 \%$ of British anesthesiologists never used monitors, and only $9.4 \%$ used them routinely [52]. In 2016, a similar survey by Chaco et al. showed a positive change: only $8.9 \%$ of the responding anesthesiologists said that they never monitored, while $31.7 \%$ did it routinely [59].

The 2017 Perioperative Monitoring Guidelines of the Chilean Anesthesiology Society also recommends that every patient who receives NMBA should be monitored until tracheal extubation and also recommends the use of objective monitoring as it is more reliable to guarantee the recovery to TOF ratio 0.9 and the exclusion of RNMB [81].

According to the 2018 South African Practice Guidelines, "a peripheral nerve stimulator to monitor neuromuscular function with double burst stimulation, train-of-four and post tetanic count facilities is an essential item (therefore the use is mandatory) and considered a minimum requirement for the safe conduct of anesthesia" [82]. An interesting appendix of the guideline (which is somewhat inconsistent with the earlier statement) emphasizes that, "the use and dose of sugammadex should be guided by quantitative neuromuscular transmission (NMT) monitoring as a minimum for all patients (as for all 
patients who receive neuromuscular blocking agents). Such monitoring should be made available in all facilities where neuromuscular blocking agents are used" [82].

The 2016 anesthesia monitoring guideline of the Finnish Society of Anaesthesiologists was meant to serve as guidance for more detailed local practice standards. It promotes the use of quantitative train-of-four monitoring to ensure adequate surgical relaxation and safe extubation [83]. The 2016 Finnish guideline abandoned clinical testing which had been part of the previous (1999) guidelines [84].

There are countries which proscribe the healthcare institutions to provide neuromuscular monitors for clinicians but do not mandate their use. The Greek minimal monitoring standards list PNSs as those devices that must be immediately available when they are needed [85]. The German Minimal standards from 2012 also state that a "relaxometer" should be available (without significant delay) when NMBAs are administered [86]. The 2018 Hungarian Patient Safety Guideline states that quantitative neuromuscular monitors must be accessible [87]. In Belgium, a "monitor of neuromuscular function" (type not specified) has been part of minimal monitoring standards for every anesthesia workstation since 2002 [88]. In Morocco, a monitor of neuromuscular function (type not specified) is prescribed for every surgical unit [89].

In 2016, Canada was in a similar situation as the above countries where the use of a peripheral nerve stimulator was not mandated when patient safety advocates called on the Canadian Anesthesiologists' Society (CAS) to mandate PNS use when NMBAs are administered [90]. At that time, Canadian Guidelines stated that a nerve stimulator only needed to be "exclusively available for each patient" [91]. The Canadian Society's reply was rather surprising “... it may reasonably be considered not essential that a nerve stimulator be applied to every patient for every moment of every procedure during which NMBDs have been used, such as is now 'required' for electrocardiography or pulse oximeter use" [92]. While the 2017 guidelines did not provide an update on this controversy [93], the 2018 guideline took one step forward, stating that, "Cautious dosing, vigilant monitoring, and the appropriate reversal of neuromuscular blocking drugs are all essential for patient safety. Neuromuscular monitoring should be utilized when non-depolarizing neuromuscular blocking agents are administered ... The following monitoring equipment shall be exclusively available for each patient: Peripheral nerve stimulator, when neuromuscular blocking drugs are used" [94]. The 2019 guidelines made no changes [95], but the 2020 revision will take another step forward. The 2020 CAS guideline will make neuromuscular monitoring mandatory when NMBAs are used and will also list PNSs as "required" for each patient, meaning that these monitors must be in continuous use throughout the administration of all anesthetics [96•]. In their special announcement, the authors of the 2020 guidelines also describe that they feel objective monitoring is superior to subjective monitoring. The reason for not currently mandating the use of objective monitoring is that it is not universally available [97].

\section{National Guidelines on Neuromuscular Blockade Management}

Another approach by national societies to NMB management is to publish detailed evidence-based guidelines that not only address monitoring but also indications of NMB and pharmacological reversal. In 2010, the Czech Society of Anesthesiology published a consensus-based practice parameter that provided a description of clinical assessment, subjective and objective monitoring, and recommended the use of objective monitoring, although did not make it obligatory [98]. In 2017, the Czech Society also published a recommendation encouraging Czech institutions to obtain quantitative neuromuscular monitoring devices as soon as possible, and to achieve this, it was proposed that monitoring devices should be included in anesthesia development tenders [99]. The Romanian Guidelines published in 2012 also summarized the then-available evidence on NMB management and concluded that "objective monitoring of the blockade will improve the patient outcome" [100].

The Spanish Society of Anesthesiology and Reanimation (SEDAR) also posted a detailed practical expert guideline on NMB management that unfortunately does not contain a date of publication [101]. It recommended that subjective monitoring should be performed in every patient when NMBAs are administered, but confusingly also recommended the use of objective monitoring, especially if repeated doses or continuous infusion of NMBAs were used, or when the patients have any neuromuscular disease. The level of recommendation at the time of these experts writing of the guideline was described as "good" [101].

The 2018 Good Clinical Practice Guideline of the Italian Society of Anesthesiology, Analgesia, Resuscitation and Intensive Care (SIAARTI) includes principles similar to the Spanish guidelines [102]. It uses the term "desirable" for objective monitoring when repeated doses or continuous infusion of NMBAs are used. However, objective monitoring is "mandatory" only in case of neuromuscular disease, severe renal and hepatic insufficiency, body mass index $>30$, and when deep block is required [102].

The French Society of Anesthesiology (SFAR) first published recommendation on neuromuscular blockade management in 2000. The short text recommended "instrumental monitoring of train-of-four stimulation" with a good level of evidence [103]. However, the wording of the recommendations was somewhat confusing regarding the differentiation between "instrumental subjective" and "instrumental objective" monitoring [103]. Contrary to the recommendations from 2000, the updated 2018 SFAR evidence-based 
guidelines on NMB management provide a detailed description of advantages and disadvantages of each monitoring modality, monitoring sites, and many aspects of NMB and reversal strategies [104•]. Specifically, the 2018 expert guidelines recommend monitoring of neuromuscular blockade in the perioperative period with the highest evidence level (G1+) and states that it is probably recommended to use TOF monitoring of the thumb to assess neuromuscular blockade in the perioperative period $(\mathrm{G} 2+)$ [104•].

In 2018, the Portuguese Anesthesiology Society also published a very detailed and advanced consensus guideline on the proper use of neuromuscular blocking and reversal agents [105•]. The guideline mandates instrumental monitoring of NMB whenever NMBAs are administered, and also recommends the use of objective monitoring with the highest evidence level $1 \mathrm{~A}$, as it is considered the only method to exclude RNMB [105•].

\section{Conclusion}

The introduction of NMBA to anesthesia practice represents a significant pharmacologic advancement that has at the same time also introduced iatrogenic complications related to RNMB. Advances in reversal agents such as sugammadex have improved patient safety; however, monitoring remains a cornerstone of optimal NMB management.

Significant gaps in knowledge within the anesthesia community regarding optimal, evidence-based NMB management have served as a significant obstacle to improving patient safety. Many anesthesiologists drastically underappreciate the scope of this issue and think RNMB happens very infrequently. While the use of quantitative monitoring can minimize the risk of RNMB and its associated complications, there has been a paucity of intuitive objective monitors. As newer devices emerge, hopefully such quantitative monitoring can serve as an important feature in optimal NMB management strategies widely utilized by the anesthesia community.

While an international panel of experts has recently developed a consensus statement strongly recommending quantitative monitoring, anesthesia societies have been slow to adopt similar guidelines. The expansion of such anesthesia specialty guidelines may represent the next step in the right direction to correct this pervasive patient safety threat.

Funding Information Open access funding provided by University of Debrecen (DE).

\section{Compliance with Ethical Standards}

Conflict of Interest Réka Nemes declares no conflict of interest. J Ross Renew has received research support in the form of a research grant from Merck Inc. (with funds to Mayo Clinic).
Human and Animal Rights and Informed Consent This article does not contain any studies with human or animal subjects performed by any of the authors.

Open Access This article is licensed under a Creative Commons Attribution 4.0 International License, which permits use, sharing, adaptation, distribution and reproduction in any medium or format, as long as you give appropriate credit to the original author(s) and the source, provide a link to the Creative Commons licence, and indicate if changes were made. The images or other third party material in this article are included in the article's Creative Commons licence, unless indicated otherwise in a credit line to the material. If material is not included in the article's Creative Commons licence and your intended use is not permitted by statutory regulation or exceeds the permitted use, you will need to obtain permission directly from the copyright holder. To view a copy of this licence, visit http://creativecommons.org/licenses/by/4.0/.

\section{References}

Papers of particular interest, published recently, have been highlighted as:

- Of importance

•- Of major importance

1. Arain SR, Kern S, Ficke DJ, Ebert TJ. Variability of duration of action of neuromuscular-blocking drugs in elderly patients. Acta Anaesthesiol Scand. 2005;49(3):312-5.

2. Debaene B, Plaud B, Dilly MP, Donati F. Residual paralysis in the PACU after a single intubating dose of nondepolarizing muscle relaxant with an intermediate duration of action. Anesthesiology. 2003;98(5):1042-8.

3. Kim KS, Cheong MA, Lee HJ, Lee JM. Tactile assessment for the reversibility of rocuronium-induced neuromuscular blockade during propofol or sevoflurane anesthesia. Anesth Analg. 2004;99(4): 1080-5.

4. Viby-Mogensen J, Jørgensen BC, Ording H. Residual curarization in the recovery room. Anesthesiology. 1979;50(6):539-41.

5. Naguib M, Kopman AF, Ensor JE. Neuromuscular monitoring and postoperative residual curarisation: a meta-analysis. Br J Anaesth. 2007;98(3):302-16.

6. Fortier LP, McKeen D, Turner K, de Médicis É, Warriner B, Jones PM, et al. The RECITE study: a Canadian prospective, multicenter study of the incidence and severity of residual neuromuscular blockade. Anesth Analg. 2015;121(2):366-72.

7. Yu B, Ouyang B, Ge S, Luo Y, Li J, Ni D, et al. RECITE-China Investigators. Incidence of postoperative residual neuromuscular blockade after general anesthesia: a prospective, multicenter, anesthetist-blind, observational study. Curr Med Res Opin. 2016;32(1):1-9.

8.• Saager L, Maiese EM, Bash LD, Meyer TA, Minkowitz H, Groudine S, et al. Incidence, risk factors, and consequences of residual neuromuscular block in the United States: the prospective, observational, multicenter RECITE-US study. J Clin Anesth. 2019;55:33-41. A recently published study showing an alarmingly high proportion of patients with residual neuromuscular blockade, as a consequence of inappropriate management of neuromuscular blockade.

9. Griffith HR, Johnson GE. The use of curare in general anesthesia. Anesthesiology. 1942;3(4):418-20.

10. Gray TC, Halton J. A milestone in anaesthesia? (d-Tubocurarine Chloride). Proc R Soc Med. 1946;39(7):400-10. 
11. Hunter JM. Reversal of residual neuromuscular block: complications associated with perioperative management of muscle relaxation. Br J Anaesth. 2017;119(suppl_1):i53-62.

12. Shafer SL. From d-tubocurarine to sugammadex: the contributions of $\mathrm{T}$. Cecil Gray to modern anaesthetic practice. Br J Anaesth. 2011;107(1):97-102.

13. Beecher HK, Todd DP. A study of the deaths associated with anesthesia and surgery. Ann Surg. 1954;140:2-34.

14. Beemer GH, Bjorksten AR, Dawson PJ, Dawson RJ, Heenan PJ, Robertson BA. Determinants of the reversal time of competitive neuromuscular block by anticholinesterases. Br J Anaesth. 1991;66(4):469-75.

15. Caldwell JE. Reversal of residual neuromuscular block with neostigmine at one to four hours after a single intubating dose of vecuronium. Anesth Analg. 1995;80(6):1168-74.

16. Eikermann M, Fassbender P, Malhotra A, Takahashi M, Kubo S, Jordan AS, et al. Unwarranted administration of acetylcholinesterase inhibitors can impair genioglossus and diaphragm muscle function. Anesthesiology. 2007;107(4):621-9.

17. Esteves S, Martins M, Barros F, Barros F, Canas M, Vitor P, et al. Incidence of postoperative residual neuromuscular blockade in the postanaesthesia care unit: an observational multicentre study in Portugal. Eur J Anaesthesiol. 2013;30(5):243-9.

18. Grosse-Sundrup M, Henneman JP, Sandberg WS, Bateman BT, Uribe JV, Nguyen NT, et al. Intermediate acting non-depolarizing neuromuscular blocking agents and risk of postoperative respiratory complications: prospective propensity score matched cohort study. BMJ. 2012;345:e6329.

19. Naguib M, Brull SJ, Johnson KB. Conceptual and technical insights into the basis of neuromuscular monitoring. Anaesthesia. 2017;72(Suppl 1):16-37.

20. Kotake Y, Ochiai R, Suzuki T, Ogawa S, Takagi S, Ozaki M, et al. Reversal with sugammadex in the absence of monitoring did not preclude residual neuromuscular block. Anesth Analg. 2013;117(2):345-51.

21. Ortiz-Gómez JR, Palacio-Abizanda FJ, Fornet-Ruiz I. Failure of sugammadex to reverse rocuronium-induced neuromuscular blockade: a case report. Eur J Anaesthesiol. 2014;31(12):708-9.

22. Sparr HJ, Vermeyen KM, Beaufort AM, Rietbergen H, Proost JH, Saldien V, et al. Early reversal of profound rocuronium-induced neuromuscular blockade by sugammadex in a randomized multicenter study: efficacy, safety, and pharmacokinetics. Anesthesiology. 2007;106(5):935-43.

23. White PF, Tufanogullari B, Sacan O, Pavlin EG, Viegas OJ, Minkowitz HS, et al. The effect of residual neuromuscular blockade on the speed of reversal with sugammadex. Anesth Analg. 2009;108(3):846-51

24. Bellod A Jr, March X, Hernandez C, Villalonga A. Delayed recurarisation after sugammadex reversal. Eur J Anaesthesiol. 2014;31(12):710-2.

25. Le Corre F, Nejmeddine S, Fatahine C, Tayar C, Marty J, Plaud B. Recurarization after sugammadex reversal in an obese patient. Can J Anaesth. 2011;58(10):944-7.

26. Asztalos L, Szabó-Maák Z, Gajdos A, Nemes R, Pongrácz A, Lengyel S, et al. Reversal of Vecuronium-induced neuromuscular blockade with low-dose sugammadex at train-of-four count of four: a randomized controlled trial. Anesthesiology. 2017;127(3):441-9.

27. Christie TH, Churchill-Davidson HC. The St Thomas's Hospital nerve stimulator in the diagnosis of prolonged apnoea. Lancet. 1958;1(7024):776.

28. Pedersen T, Viby-Mogensen J, Bang U, Olsen NV, Jensen E, Engboek J. Does perioperative tactile evaluation of the train-offour response influence the frequency of postoperative residual neuromuscular blockade? Anesthesiology. 1990;73(5):835-9.
29. Cammu G, De Witte J, De Veylder J, Byttebier G, Vandeput D, Foubert L, et al. Postoperative residual paralysis in outpatients versus inpatients. Anesth Analg. 2006;102(2):426-9.

30. Fruergaard K, Viby-Mogensen J, Berg H, el Mahdy AM. Tactile evaluation of the response to double burst stimulation decreases, but does not eliminate, the problem of postoperative residual paralysis. Acta Anaesthesiol Scand. 1998;42(10):1168-74.

31. Shorten GD, Merk H, Sieber T. Perioperative train-of-four monitoring and residual curarization. Can J Anaesth. 1995;42(8):7115 .

32. Viby-Mogensen J, Jensen NH, Engbaek J, Ording H, Skovgaard LT, Chraemmer-Jørgensen B. Tactile and visual evaluation of the response to train-of-four nerve stimulation. Anesthesiology. 1985;63(4):440-3.

33. Drenck NE, Ueda N, Olsen NV, Engbaek J, Jensen E, Skovgaard LT, et al. Manual evaluation of residual curarization using double burst stimulation: a comparison with train-of-four. Anesthesiology. 1989;70(4):578-81.

34. Capron F, Fortier LP, Racine S, Donati F. Tactile fade detection with hand or wrist stimulation using train-of-four, double-burst stimulation, 50-hertz tetanus, 100-hertz tetanus, and acceleromyography. Anesth Analg. 2006;102(5):1578-84.

35. Murphy GS, Szokol JW, Marymont JH, Greenberg SB, Avram MJ, Vender JS, et al. Intraoperative acceleromyographic monitoring reduces the risk of residual neuromuscular blockade and adverse respiratory events in the postanesthesia care unit. Anesthesiology. 2008;109(3):389-98.

36. Murphy GS, Szokol JW, Avram MJ, Greenberg SB, Marymont $\mathrm{JH}$, Vender JS, et al. Intraoperative acceleromyography monitoring reduces symptoms of muscle weakness and improves quality of recovery in the early postoperative period. Anesthesiology. 2011;115(5):946-54.

37.• Naguib M, Brull SJ, Kopman AF, Hunter JM, Fülesdi B, Arkes HR, et al. Consensus statement on perioperative use of neuromuscular monitoring. Anesth Analg. 2018;127(1):71-80. A consensus statement authored by an international panel of experts on evidence-based neuromuscular monitoring. It provides definitions of neuromuscular monitoring modalities and gives a standardized description of levels of neuromuscular blockade management.

38. Viby-Mogensen J, Jensen E, Werner M, Nielsen HK. Measurement of acceleration: a new method of monitoring neuromuscular function. Acta Anaesthesiol Scand. 1988;32(1):45-8.

39. Jensen E, Viby-Mogensen J, Bang U. The Accelograph: a new neuromuscular transmission monitor. Acta Anaesthesiol Scand. 1988;32(1):49-52.

40. Baillard C, Bourdiau S, Le Toumelin P, Ait Kaci F, Riou B, Cupa $\mathrm{M}$, et al. Assessing residual neuromuscular blockade using acceleromyography can be deceptive in postoperative awake patients. Anesth Analg. 2004;98(3):854-7.

41. Söderström CM, Eskildsen KZ, Gätke MR, Staehr-Rye AK. Objective neuromuscular monitoring of neuromuscular blockade in Denmark: an online-based survey of current practice. Acta Anaesthesiol Scand. 2017;61(6):619-26.

42. Baillard C, Clec'h C, Catineau J, Salhi F, Gehan G, Cupa M, et al. Postoperative residual neuromuscular block: a survey of management. Br J Anaesth. 2005;95(5):622-6.

43. Todd MM, Hindman BJ, King BJ. The implementation of quantitative electromyographic neuromuscular monitoring in an academic anesthesia department. Anesth Analg. 2014;119(2):32331.

44. Todd MM, Hindman BJ. The implementation of quantitative electromyographic neuromuscular monitoring in an academic anesthesia department: follow-up observations. Anesth Analg. 2015;121(3):836-8. 
45. Milne JI, Ong CS, Ong JS, Cheung KC, Schauer AA, Buttar SB, et al. The influence of introducing unrestricted access to sugammadex and quantitative neuromuscular monitors on the incidence of residual neuromuscular block at a tertiary teaching hospital. An audit of 'real-life'. Anaesth Intensive Care. 2016;44(6):784.

46. McGill N, Yoon M. A quality improvement program involving protocolised reversal from neuromuscular block. Anaesthesia. 2017;72(9):1152-3.

47. Brull SJ. Indicators of recovery of neuromuscular function: time for change? Anesthesiology. 1997;86(4):755-7.

48. Kopman AF. Managing neuromuscular block: where are the guidelines? Anesth Analg. 2010;111(1):9-10.

49. Eriksson LI. Evidence-based practice and neuromuscular monitoring: it's time for routine quantitative assessment. Anesthesiology. 2003;98(5):1037-9.

50. El-Orbany M. Objective monitoring of neuromuscular block should become the standard of care. Acta Anaesthesiol Scand. 2009;53(6):837.

51. Sorgenfrei IF, Viby-Mogensen J, Swiatek FA. Does evidence lead to a change in clinical practice? Danish anaesthetists' and nurse anesthetists' clinical practice and knowledge of postoperative residual curarization. Ugeskr Laeger. 2005;167(41):3878-82.

52. Grayling M, Sweeney BP. Recovery from neuromuscular blockade: a survey of practice. Anaesthesia. 2007;62(8):806-9.

53. Phillips S, Stewart PA, Bilgin AB. A survey of the management of neuromuscular blockade monitoring in Australia and New Zealand. Anaesth Intensive Care. 2013;41(3):374-9.

54. Di Marco P, Della Rocca G, Iannuccelli F, Pompei L, Reale C, Pietropaoli P. Knowledge of residual curarization: an Italian survey. Acta Anaesthesiol Scand. 2010;54(3):307-12.

55. Naguib M, Kopman AF, Lien CA, Hunter JM, Lopez A, Brull SJ. A survey of current management of neuromuscular block in the United States and Europe. Anesth Analg. 2010;111(1):110-9.

56. Murphy GS, Brull SJ. Residual neuromuscular block: lessons unlearned. Part I: definitions, incidence, and adverse physiologic effects of residual neuromuscular block. Anesth Analg. 2010;111(1):120-8.

57. Brull SJ, Murphy GS. Residual neuromuscular block: lessons unlearned. Part II: methods to reduce the risk of residual weakness. Anesth Analg. 2010;111(1):129-40.

58. Brull SJ, Kopman AF. Current status of neuromuscular reversal and monitoring: challenges and opportunities. Anesthesiology. 2017;126(1):173-90.

59. Chacko CJ, Haldar M. Survey on neuromuscular management. J Anaesthesiol Clin Pharmacol. 2016;32(1):122.

60. Colegrave N, Billard V, Motamed C, Bourgain JL. Comparison of the TOF-Scan acceleromyograph to TOF-Watch SX: influence of calibration. Anaesth Crit Care Pain Med. 2016;35(3):223-7.

61. Murphy GS, Szokol JW, Avram MJ, Greenberg SB, Shear TD, Deshur M, et al. Comparison of the TOFscan and the TOF-Watch SX during recovery of neuromuscular function. Anesthesiology. 2018;129(5):880-8.

62. Rodiera J, Serradell A, Alvarez-Gomez JA, Aliaga L. The cuff method: a pilot study of a new method of monitoring neuromuscular function. Acta Anaesthesiol Scand. 2005;49(10):1552-8.

63. Veiga Ruiz G, et al. Monitoring intraoperative neuromuscular blockade and blood pressure with one device (TOF-Cuff): a comparative study with mechanomyography and invasive blood pressure. Rev Esp Anestesiol Reanim. 2017;64(10):560-7.

64. Kazuma S, Wakasugi K, Hagiwara H, Yamakage M. Comparative study of TOF-Cuff, a new neuromuscular blockade monitor, and TOF-Watch, an acceleromyography. Anesth Analg. 2019;129(1): e16-e9.
65. Krijtenburg P, et al. Comparison of the TOF-Cuff((R)) monitor with electromyography and acceleromyography during recovery from neuromuscular block. Br J Anaesth. 2019;122(2):e22-e4.

66. Nemes R, Nagy G, Murphy GS, Logvinov II, Fülesdi B, Renew JR. Awake volunteer pain scores during neuromuscular monitoring. Anesth Analg. 2019;130(4):941-8.

67. Bowdle A, Bussey L, Michaelsen K, Jelacic S, Nair B, Togashi K, et al. A comparison of a prototype electromyograph vs. a mechanomyograph and an acceleromyograph for assessment of neuromuscular blockade. Anaesthesia. 2019;75(2):187-95.

68. Naguib M, Brull SJ, Hunter JM, Kopman AF, Fülesdi B, Johnson $\mathrm{KB}$, et al. Anesthesiologists' overconfidence in their perceived knowledge of $\mathrm{N}$-neuromuscular monitoring and its relevance to all aspects of medical practice: an international survey. Anesth Analg. 2019;128(6):1118-26.

69. https://www.asahq.org/standards-and-guidelines/standards-forbasic-anesthetic-monitoring. Last accessed: December $4^{\text {th }}, 2019$.

70. Apfelbaum JL, Silverstein JH, Chung FF, Connis RT, Fillmore RB, Hunt SE, et al. American Society of Anesthesiologists Task Force on Postanesthetic Care: Practice guidelines for postanesthetic care: an updated report by the American Society of Anesthesiologists Task Force on Postanesthetic Care. Anesthesiology. 2013;118(2):291-307.

71. Merry AF, Cooper JB, Soyannwo O, Wilson IH, Eichhorn JH. International standards for a safe practice of anesthesia 2010. Can J Anaesth. 2010;57(11):1027-34.

72. https://www.nafweb.com/dokumenter/norsk-standard-foranestesi-2016.pdf. Last accessed: December 4th, 2019.

73. https://anesth.or.jp/files/pdf/monitor3_20190509.pdf. Last accessed: December 2nd, 2019.

74. https://sgar-ssar.ch/fileadmin/user upload/sgar-ssar/public/ Services/Richtlinien_Standards_und_Empfehlungen/St_E 2012_d_Minirev_29012014.pdf. Last accessed: December 4th, 2019.

75. https://www.anesthesiologie.nl/uploads/files/KD_Leidraad Anesthesiologische_perioperatieve_zorg_11032019.pdf. Last accessed: December $4^{\text {th }}, 2019$.

76. http://www.dasaim.dk/wp-content/uploads/2019/05/ Rekommandation-for-an\%C3\%A6stesi-2017.pdf. Last accessed: December $4^{\text {th }}, 2019$.

77. Söderström CM, Eskildsen KZ, Gätke MR, Staehr-Rye AK. Response to 'Objective neuromuscular monitoring: the challenges limiting its use' by Dr. El-Orbany Acta Anaesthesiol Scand. 2018;62(2):268-9.

78. http://www.anzca.edu.au/documents/ps18-2015-guidelines-onmonitoring-during-anaesthe.pdf. Last accessed: December 4th, 2019.

79. http://www.anzca.edu.au/documents/ps18bp-2017.pdf. Last accessed: December 4th, 2019.

80. Checketts MR, Alladi R, Ferguson K, Gemmell L, Handy JM, Klein AA, et al. Association of Anaesthetists of Great Britain and Ireland. Recommendations for standards of monitoring during anaesthesia and recovery 2015: Association of Anaesthetists of Great Britain and Ireland. Anaesthesia. 2016;71(1):85-93.

81. https://www.sachile.cl/upfiles/re/RC_Disponibilidad_y_Uso_de Monitorizacion_Perioperatoria_SACH.pdf. Last accessed: December $4^{\text {th }}, 2019$.

82. https://sasaapi.sasaweb.com/Document/SAJAA(V24N1) 2061SASAPracticeGuidelines_V12_636803016948256880.pdf. Last accessed: December $4^{\text {th }}, 2019$.

83. https://www.say.fi/application/files/1814/8796/7686/SAYn anestesiavalvontaa_koskevat_suositukset.pdf. Last accessed: December $4^{\text {th }}, 2019$.

84. https://www.say.fi/application/files/6314/5392/9236/1 suomen anestesiologiyhdistyksen_suositukset_vuodelta_1999.pdf. Last accessed: December $4^{\text {th }}, 2019$. 
85. https://anaesthesiology.gr/media/File/pdf/GL10.pdf. Last accessed: December $4^{\text {th }}, 2019$.

86. https://www.bda.de/docman/alle-dokumente-fuer-suchindex/ oeffentlich/empfehlungen/569-mindestanforderungen-an-denanaesthesiologischen-arbeitsplatz/file.html. Last accessed: December $4^{\text {th }}, 2019$.

87. Bede A, Hupuczi P, Nagy L, Ökrös I, Újhelyi E. Az Egészségügyi Szakmai Kollégium Aneszteziológiai és Intenzív Terápiás Tanácsa, A Perioperatív betegbiztonság irányelve az anesztéziában 2018. Aneszteziológia és Intenzív Terápia. 2019;49(2):10-6.

88. Belgian Professional Association of Specialists in Anesthesia and Resuscitation, Belgian standards for patient safety in anesthesia. An update. Acta Anaesthesiol Belg. 2002;53(1):5-9.

89. http://smar.ma/uploads/documents/referentiels_SMAR2016.pdf. Last accessed: December $4^{\text {th }}, 2019$.

90. Hudson RJ. Neuromuscular monitoring should be required when neuromuscular blocking drugs are used: is it time to change the Canadian guidelines? Can J Anaesth. 2016;63(7):891.

91. Merchant R, Chartrand D, Dain S, Dobson G, Kurrek MM, Lagacé A, et al. Guidelines to the practice of anesthesia - revised edition 2016. Can J Anaesth. 2016;63(1):86-112.

92. Dobson G, Merchant RN. In reply: neuromuscular monitoring should be required when neuromuscular blocking drugs are used: is it time to change the Canadian guidelines? Can J Anaesth. 2016;63(7):892-3.

93. Dobson G, Chong M, Chow L, Flexman A, Kurrek M, Laflamme $\mathrm{C}$, et al. Guidelines to the practice of anesthesia - revised edition 2017. Can J Anaesth. 2017;64(1):65-91.

94. Dobson G, Chong M, Chow L, Flexman A, Kurrek M, Laflamme $\mathrm{C}$, et al. Guidelines to the practice of anesthesia - revised edition 2018. Can J Anaesth. 2018;65(1):76-104.

95. Dobson G, Chow L, Flexman A, Hurdle H, Kurrek M, Laflamme $\mathrm{C}$, et al. Guidelines to the practice of anesthesia - revised edition 2019. Can J Anaesth. 2019;66(1):75-108.

96. Dobson G, Chow L, Filteau L, Flexman A, Hurdle H, Kurrek M, et al. Guidelines to the practice of anesthesia - revised edition
2020. Can J Anaesth. 2019;67(1):64-99. A recently published progressive anesthesia practice guideline, which mandates the use of peripheral nerve stimulators but strongly recommends objective monitoring.

97. Dobson GR. Special announcement: guidelines to the practice of anesthesia-revised edition 2020. Can J Anaesth. 2019;67(1):64 99.

98. https://www.csarim.cz/content/uploads/2018/11/practiceparameters-for-the-safe-and-effective-use-of-neuromuscularblocking-drugs-in-anaesthesia-2010.pdf. Last accessed: December 4th, 2019.

99. https://www.csarim.cz/content/uploads/2018/11/stanovisko-kpristrojove-monitoraci-hloubky-nervosvalove-blokady.pdf. Last accessed: December $4^{\text {th }}, 2019$.

100. https://www.atitimisoara.ro/educatie-medicala.php. Last accessed: December $4^{\text {th }}, 2019$.

101. https://www.sedar.es/images/site/GuiasClinicas/SEDAR/bnm. pdf. Last accessed: December $4^{\text {th }}, 2019$.

102. http://www.siaarti.it/standardclinici/Buone\%20Pratiche\% 20Cliniche\%20SIAARTI\% 20-\%20Miorisoluzione, \% 20monitoraggio\%20neuromuscolare\%20e\%20antagonismo.pdf. Last accessed: December $4^{\text {th }}, 2019$.

103. Indications of neuromuscular blockade in anaesthesia. Short text. Ann Fr Anesth Reanim 2000; 19(Suppl 2):352s-5s.

104. https://sfar.org/wp-content/uploads/2018/10/2_RFE-CURARE-3. pdf. Last accessed: December $4^{\text {th }}, 2019$. A detailed and evidence-based national guideline on neuromuscular blockade management strongly recommending objective monitoring.

105. http://www.spanestesiologia.pt/ficheiros/Bloqueio\% 20NeuroMuscular.pdf. Last accessed: December $2^{\text {nd }}, 2019$. A detailed and evidence-based national guideline on neuromuscular blockade management mandating objective monitoring whenever neuromuscular blocking agents are used.

Publisher's Note Springer Nature remains neutral with regard to jurisdictional claims in published maps and institutional affiliations. 